\title{
A knowledge-to-action approach to food fortification: Guiding principles for the design of fortification programs as a means of effectively addressing micronutrient malnutrition
}

\author{
Laura A. Rowe*, David M. Dodson \\ Project Healthy Children, Cambridge, USA; ${ }^{*}$ Corresponding Author: lrowe@projecthealthychildren.org
}

Received 28 August 2012; revised 26 September 2012; accepted 5 October 2012

\begin{abstract}
The gap that exists between research and the dissemination and implementation of research findings has been well established. Food fortification, one of the most cost-effective means of addressing micronutrient malnutrition, is no exception. With decades of implementation experience, there is need to strengthen mechanisms that effectively broadcast proven strategies to promote the successful implementation of fortification programs in changing, challenging, and dynamic environments. This requires clear channels of communication, well-defined in-country leadership, and a streamlined and focused approach that can be adapted to country-specific contexts. Based on experience designing and implementing fortification programs throughout Africa and a broad understanding of past successes and failures, a model is proposed that articulates often over-looked program elements critical to design and implementation.
\end{abstract}

Keywords: Food Fortification; Micronutrient Malnutrition; Program Design; Program Implementation; Leadership; Africa

\section{INTRODUCTION}

There is a wealth of literature on the "knowing-doing gap" [1-7], or the gap that exists between research, both in medicine and in public health, and the dissemination and implementation of research findings [1]. In many cases, this lack of uptake is due to the fact that an intervention is developed without full consideration to the context and setting in which it will be implemented, rendering it of little use [7]. In other cases, it is due to the challenge of effectively broadcasting proven strategies in clear and concise messages or frameworks that allow for scaling-up in changing, challenging, and dynamic environments [8].

This paper seeks to add to the already existing literature on how to implement national food fortification programs in a way that addresses the "knowing-doing" gap by offering a streamlined model that facilitates moving from evidence to application. Based on Project Healthy Children's (PHC) experience assisting governments in the design and implementation of national food fortification programs in Rwanda and Malawi, in this paper we 1) describe how nationwide, mandatory food fortification programs, often missing from national agendas, are distinct in how they address the problem of malnutrition; and 2) document four core, arguably intangible and often overlooked, principles needed to solidify engagement, including a streamlined data collection framework that unravels the complexity of fortification as an intervention in resource-constrained environments.

Founded in 2000, Project Healthy Children is a small nonprofit organization that assists governments and industry in designing and implementing countrywide, market-based, mandatory food fortification programs to address deficiencies in critical micronutrients. PHC has completed a program in Honduras and is currently operating programs in Rwanda, Malawi, Burundi, Liberia, and a small-scale fortification program in Nepal.

\section{THE PROBLEM}

Never recorded on a death certificate, micronutrient malnutrition is responsible for the deaths of over 100 children every hour of every day due to a limited quality of food, foundational to basic biological functions [9]. Each year, 1.1 million children under the age of five die due to vitamin A and zinc deficiencies [10]. A lack of iron causes over 600,000 stillbirths or neonatal deaths and over 100,000 maternal deaths during pregnancy [11]. 
Survival only means a compromised system with damaging long-term effects. Annually, 350,000 cases of childhood blindness and countless infections could be prevented with sufficient intake of vitamin A [10]. Due to maternal folate deficiency, 300,000 children are born each year with severe birth defects [12] and 18 million babies are born mentally impaired as a result of maternal iodine deficiency leading to a loss of up to 15 IQ points and an earning potential, as adults, of at least $20 \%$ less than their healthy counterparts [9]. This is why children can go to school year after year and not actually learn anything.

Finally, children undernourished in utero and in their early years have a higher risk of developing chronic diseases later in life such as diabetes and cardiovascular diseases [13,14].

All of this undermines the goals of development interventions, and leads to what has been estimated to be an annual GDP loss of 2\% - 3\% for developing nations $[15,16]$, with direct costs estimated between US\$20 to $\$ 30$ billion every year [9]. And this does not include economic implications associated with an increase in chronic disease.

The World Health Organization (WHO) and the United Nations Food and Agriculture Organization (FAO) have identified four main strategies for improving micronutrient malnutrition: food fortification, supplementation, nutrition education, and disease control measures [17].

Of these, food fortification has proven to be one of the most cost-effective interventions to advance global welfare (not just health) [18]. This unique intervention involves adding critical vitamins and minerals to staple foods during the production process, which are commonly and consistently consumed by the target population (generally women and children since they are the most at risk) in order to address a nutritional gap. Fortification provides nutritional benefits without requiring consumers to change eating habits and often without requiring changes in purchase patterns since it targets foods the population is already consuming, overcoming an obstacles often experienced by other interventions such as supplementation and dietary diversity. Foods commonly fortified in the developing world include maize and wheat flour, cooking oil, rice, and sugar.

However, despite the desirable aspects of fortification, a vast amount of evidence on fortification's health and economic impacts, $[17,19,20]$ and significant experience in implementation [21-27], uptake in countries has been slow [27]. This, in many circumstances, is due to the complexity of factors and actors involved in implementtation [27], often earning fortification the distinction of being an unwieldy intervention to implement. The authors would argue this does not have to be the case.

How do we move from what we know about fortifica- tion to effectively applying it in dynamic, changing environments? How do we ensure programs are built in ways that allow for life after external support? How do we cope with the inherent complexity of the intervention? We address these questions in the following three sections. First, we provide evidence of why fortification is unique and why it should be a priority in efforts to address malnutrition. Second, we provide a brief description of the local context from which the proposed model we offer emerged. Finally, we draw heavily on our experiences by describing often overlooked and intangible elements found in the seams of successful programs and a data collection framework critical to a program's foundation.

\section{THE UNIQUE ROLE OF FOOD FORTIFICATION}

National, mandatory food fortification (distinct from targeted or market-driven fortification) offers a unique advantage over other nutrition interventions in that it is incredibly cheap to implement [17,19] requiring only cents per person per year [19], relies on the private sector and already existing market delivery systems [20], requires limited behavior change, $[27,28]$ and holds the greatest potential for reaching the largest number of people [29] in the most sustainable way.

It is not surprising then that, in 2008, when a group of economic experts came together in the Copenhagen Consensus with the goal of identifying priorities that would address the ten greatest global challenges with an eye to economic costs and benefits, fortification ranked number three [18].

Food fortification is a public health intervention that is adopted by and delivered through the private sector using its delivery expertise and efficiency, with strong support from the government. Few other large-scale programs use this method of delivery. Integral to the success of the program is close collaboration and coordination between and across multiple ministries and agencies. Although initially complicating its introduction, this allows for a program that is completely self-sustaining, a program that benefits from private industry strengths, and a strategy that is institutionalized within and owned by the country, avoiding long-term dependency on outside assistance.

Government mandate ensures private industry complies. This is essential to level the playing field for all producers. Upfront investments by industry are recouped through increased demand from social marketing campaigns and/or negligible price increases of between $1 \%$ $2 \%$, less than normal market price fluctuations [17].

Numerous programs have demonstrated the effectiveness of fortification: In Guatemala, mandatory sugar fortification introduced in 1988 reduced the prevalence of 
vitamin A deficiency from $22 \%$ to $5 \%$ in one year [22]. In Chile, the addition of folic acid to wheat flour led to a 3-to-4-fold increase in blood folate levels in women of reproductive age and a decrease in the neural tube defects spina bifida and anencephaly by $51 \%$ and $46 \%$, respectively [23]. After South Africa mandated the addition of folic acid to wheat and maize flour in 2003, overall neural tube defects dropped by $30 \%$ with spina bifida dropping 41.6\% [24]. In China, sentinel surveys in 21 health centers found that anemia dropped by approximately one third following fortification of soy sauce with iron in 2003 [25]. And in Canada, four years after folic acid fortification of grain products became mandatory in 1998, the rate of neural tube defects fell by $46 \%$ [26].

\section{LOCAL CONTEXT: WHERE THE MODEL WAS GENERATED}

In light of this evidence and fortification's unique advantages, the Rwandan Ministry of Health $(\mathrm{MoH})$ made the strategic decision in 2007 to include food fortification in their national nutrition agenda in order to address the persistent prevalence of vitamin and mineral deficiencies. Similarly, in the early 2000's, Malawi's Department of Nutrition and HIV/AIDS under the Office of the President and Cabinet (OPC) decided that a national food fortification program was critical to address the country's high rate of micronutrient malnutrition, a program that was introduced but, which later, began to falter.

It is within this context that Project Healthy Children (PHC), a US-based non-governmental organization, took on the role of fortification advisor to the governments of Rwanda and Malawi, in 2007 and 2011, respectively. Work began with country-level data collection and analysis to gauge government and industry readiness, country need for fortification, and whether a favorable environment for implementation existed. This involved strong engagement with government and industry and collaboration with numerous in-country partners. It is this datadriven approach along with steps essential to implementing a fortification program $[17,27,28]$ that we offer as a model for replication.

At the time of writing, Malawi's first batch of fortified sugar and Rwanda's first batch of fortified maize flour had just hit the markets. Although a solid monitoring and surveillance system will be the true test of success for these programs, the model employed was a critical factor in achieving program deployment, institutionalization within government structures, and facilitation of efficient communication channels. Although this model should not be blindly adopted without due consideration to the unique country context, the core elements and general sequence outlined should provide future programs with a solid foundation upon which to begin.

\section{A MODEL FOR DISSEMINATION: MOVING FROM EVIDENCE TO APPLICATION}

Coordination across ministries and among multiple stakeholders is the nature of any successful fortification program. It is a dynamic and multi-faceted intervention that must be approached with creative flexibility. A program can falter or thrive based on the quality of multisectorial collaborations between the public sector (government), the private sector (food producers), and civil society (consumers) [20]; on the ability of multiple ministries within government to work together; and on the degree of committed and sustained leadership from within the country. Taking into account commercial product viability, trade dynamics, technical constraints, and the sensitivity of an intervention dealing with a country's food supply, there is clear need to approach this intervenetion, both from a technological and a policy perspective, with persistence, a close eye to the local context, and a consistent strategy that addresses the needs and concerns of all pertinent players. The model that emerged from PHC's experience, which focuses on the policy perspective of programming, involves a set of four core principles, arguably intangible and often overlooked, vital to the sustainability of end results. Although these four principles could be relevant for the successful implementation of any health delivery program, they are particularly relevant for fortification because their omission has so often lead to program faltering [20,22,27,29]. Its design, application, and management should be adapted to suite the local context.

Principle 1: Government commitment to and prioritization of a national, mandatory program.

Government commitment to a mandatory program from the beginning is the best means to ensure a sustainable program [17]. A mandatory program allows for consistent monitoring and clear signals to trade partners and creates a level playing field facilitating industry compliance. Establishing a mandatory program means, in most cases, drafting legislation, which requires strong backing and prioritization of the program by the government. Ensuring this from inception is vital. Government prioritization also entails a commitment to advocacy campaigns and the inclusion and harmonization of fortification in national health and nutrition policies.

Principle 2: Focused guidance through an identified catalyst in support of a national, mandatory program.

Effectively guiding multiple players is a central challenge to any fortification program, whether by an outside organization (i.e. an INGO or donor) or a national host institution. Due to competing demands, there is often not a lead agency within the country that can dedicate full 
attention to fortification. It is, therefore, advantageous to have an external entity to act as a catalyst, assisting in the identification of priorities, providing intense focus, and pushing work streams forward. A Memorandum of Understanding (MOU) with a "home" Ministry is helpful to ensure objectives are clearly communicated and outlined, allocation of responsibilities is agreed upon, and joint expectations are met.

The objective is to strike the right balance between catalyst and supporter, within the context of national priorities, and to provide focused attention needed to advance the program.

Principle 3: A data-driven approach that includes a focus on robust monitoring.

The data-collection framework that emerged from PHC's experience involves three general phases of engagement: research, design, and implementation that focus consistently on the areas of nutrition policy and legislation, food fortification standards, industry implementation, and government monitoring and social marketing. This framework acts as a blueprint to guide program implementers throughout the life of a program while ensuring critical program components are not forgotten. Program managers should revisit these four areas on a frequent basis to gauge program progress and gaps that need to be filled.

The research or data collection phase captures a concise picture of what the health, nutrition, consumption, and political environments look like. It includes understanding the current situation as it pertains to macro- and micronutrient deficiencies, dietary consumption patterns, market access by the most vulnerable, trade patterns, industry consolidation, national standards development processes, current regulatory monitoring systems, and national analytical testing capabilities.

The design phase involves identifying and bringing together all relevant stakeholders and utilizing the information gathered in the research phase to answer the question: what needs to be done based on what we know exists or does not exist within the areas of nutrition policy and legislation, food fortification standards, industry implementation, and government monitoring and social marketing? For example, which foods are most important

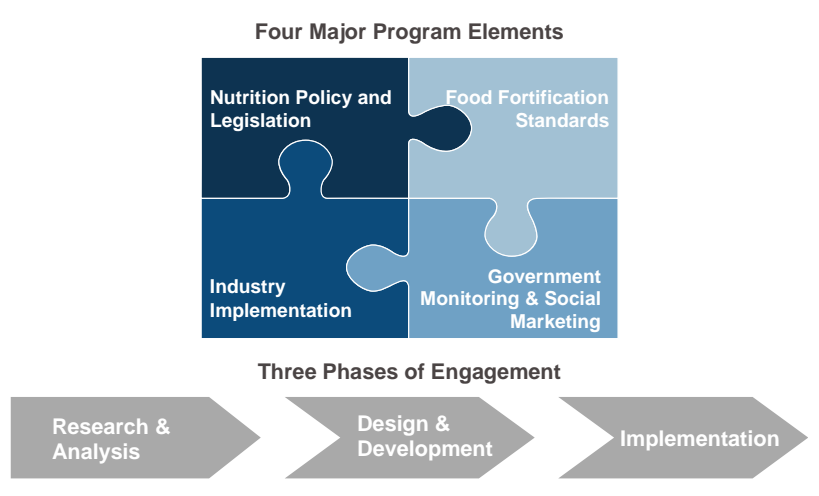

for fortification with what micronutrients and at what levels? Where should fortification as a strategy be included in existing national policies and how should it be harmonized with existing nutrition interventions? What staple food industries exist domestically and where are imports being sourced from? What is required for domestic facilities to incorporate fortification in their production lines? What government bodies are responsible for monitoring and inspecting foods? What additional training capacity is needed to ensure appropriate sampling and testing of fortified products occurs at the market, border, household, and industry levels?

This is a critical time to establish a public-private partnership with representation from all pertinent stakeholders to serve as the guiding body for fortification activities. Additionally, it is an important time to critically examine past fortification programs that have and have not succeeded. Although fortification has been going on successfully since the 1920s, there have been programs that have faltered. Understanding why they faltered is vital to preventing similar missteps. As a result, implementers should make a habit of reviewing past programs.

Finally, the implementation phase ensures safe, effecttive fortified foods reach the target population through active industry engagement in a way that can be appropriately monitored, measured, and adjusted for, as population needs change. This phase involves ensuring: appropriate legislation is passed that makes fortification mandatory; on the industry side, appropriate lines of production are in place, needed equipment and premix are sourced, and appropriate quality assurance and control measures are functioning; social marketing campaigns around the role of fortified food in healthy diets are disseminated; effective government monitoring is taking place and samples meet the designated regulations; and finally, a surveillance system is designed to evaluate the long-term impact of the program on the population's micronutrient status. This monitoring component, both at the industry and government levels, is particularly vital. Even if all other aspect of programming have been successful, if fortified foods are not routinely monitored to ensure levels fall within the designated appropriate ranges, the program will have little to no impact, will risk losing support, and could potentially risk doing harm instead of good.

Principle 4: Systemic, national leadership within a national guiding body

Strong leadership is at the core of any successful program and should be a primary focus throughout the life of the program. A multi-sectorial alliance driven by government and industry and led by in-country leaders should be established to guide fortification activities. Without strong national leadership to ensure stakeholder representation and to drive in-country priorities and in- 
dustry implementation, little long-term sustainability or country ownership can be attained. Such a guiding body often takes the form of a National Fortification Alliance (NFA) [20]. In our experience, such a structure is by far the most useful mechanism that a program can establish. In fact, one of the primary reasons for Rwanda's success was the early identification of strong leadership and the formation of a cohesive NFA.

\section{CONCLUSIONS}

National, mandatory fortification programs hold great potential for impacting widespread change in a populations' nutritional status; numerous studies demonstrate fortification's effectiveness and feasibility (30 - 34). Few, however, articulate often over-looked program elements critical to design and implementation (8).

To bridge the "knowing-doing" gap in food fortification programming, this paper outlines a streamlined model that articulates elements vital to design and implementation, while emphasizing the need to pay particular attention to leadership and the role individuals and organizations play in the process.

We have come so far technologically in regard to food fortification. There is now increased need for focused attention on creativity, past successes and failures, and the identification of in-country leadership to carry the program on. These elements have the potential, when applied with an understanding and sensitivity to the local context, to promote successful uptake and to ensure longterm sustainability and ownership enabling fortification programs to reach the greatest number of people in the most efficient and effective manner.

\section{ACKNOWLEDGEMENTS}

We thank Molly Clark-Barol for helpful editing comments and Meagan Livergood for assisting in obtaining literature sources. We would also like to thank each of PHC's Country Coordinators who work tirelessly to guide governments in the design and implementation process to ensure national food fortification becomes a reality: Elvis Gakuba in Rwanda and Burundi, Martha Pigott in Malawi, and Molly Clark-Barol in Liberia. Finally, thanks goes to those in-country leaders whom without, none of this work would be possible.

\section{REFERENCES}

[1] Haines, A., Kuruvilla, S. and Borchert, M. (2004) Bridging the implementation gap between knowledge and action for health. Bulletin of the World Health Organization, 82, 724-732.

[2] Melgaard, B. (2004) From research to action-A bridge to be crossed. Bulletin of the World Health Organization, 82, 723.

[3] Pfeffer, J. and Sutton, R.I. (2000) The knowing doing gap.
Harvard Business School Press, Boston.

[4] Rogers, E.M., Singhal, A. and Quinlan, M.M. (2009) Diffusion of innovations. In: Stacks, D. and Salwen, M., Eds., An Integrated Approach to Communication Theory and Research, Lawrence Erlbaum Associates, Mahwah, 418434.

[5] Pang, T., Pablos-Mendez, A. and IJsselmuiden, C. (2004) From Bangkok to Mexico: Towards a framework for turning knowledge into action to improve health systems. Bulletin of the World Health Organization, 82, 720-721.

[6] McCannon, C.J., Berwick, D.M. and Massoud, M.R. (2007) The science of large-scale change in global health. Journal of the American Medical Association, 298, 19341939. doi:10.1001/jama.298.16.1937

[7] Green, L.W., Ottoson, J.M., Garcia, C. and Hiatt, R.A. (2009) Diffusion theory and knowledge dissemination, utilization, and integration in public health. Annual Review of Public Health, 30, 151-174.

doi:10.1146/annurev.publhealth.031308.100049

[8] Committee on Micronutrient Deficiency (1998) Prevention of micronutrient deficiencies: Tools for policymakers and public health workers. National Academy Press, Washington DC.

[9] Rawe, K., Jayasinghe, D., Mason, F., Davis, A., Pizzini, M., Garde, M. and Crosby, L. (2012) A life free from hunger: Tacking child malnutrition.

http://www.savethechildren.org.uk/sites/default/files/docs /A\%20Life\%20Free\%20From\%20Hunger\%20UK\%20lo w\%20res.pdf

[10] Micronutrient Initiative (2009) Investing in the future: A united call to action on vitamin and mineral deficiencies. Micronutrient Initiative, Ottawa.

[11] Solomons, N.W. (2011) Sight and life luncheon forum on contributions of micronutrients to achieve the MDGs. Sight and Life, 25, 76-80.

[12] Center for Disease Control (CDC) (2012) March of dimes. http://www.cdc.gov/immpact/micronutrients/index.html\# Folate

[13] Victoria, C.G., Adair, L., Fall, C., Hallal, P.C., Martorell, R., Richter, L. and Sachdev, H.S. (2008) Maternal and child undernutrition: Consequences for adult health and human capital. The Lancet, 371, 340-357. doi:10.1016/S0140-6736(07)61692-4

[14] Barker, D.J.P. (1998) In utero programming of chronic disease. Clinical Science, 95, 115-128. doi:10.1042/CS19980019

[15] Mundial, B. (2006) Repositioning nutrition as central to development: A strategy for large-scale action. World Bank Publications, Washington DC.

[16] Horton, S. (1999) The economics of nutritional interventions. In: Semba, R.D. and Bloem, M.W., Eds., Nutrition and Health in Developing Countries. Humana Press, Inc., Totawa, 859-871.

[17] World Health Organization (2006) Guidelines on food fortification with micronutrients. World Health Organization, Geneva.

[18] (2008) Copenhagen consensus results. 
http://www.copenhagenconsensus.com/Files/Filer/CC08/ Presse\%20\%20result/CC08_results_FINAL.pdf

[19] Horton, S. (2006) The economics of food fortification. Journal of Nutrition, 136, 1068-1071.

[20] Kim, S.S. (2009) Developing a national food fortification program in the dominican republic. In: Pinstrup-Anderson, P. and Cheng, F., Eds., Case Studies in Food Policy for Developing Countries, Cornell University Press, Ithaca, 57-68.

[21] Bishai, D. and Nalubola, R. (2002) The history of food fortification in the US: It's relevance for current fortification efforts in developing countries. Economic Development and Cultural Change, 51, 37-53. doi:10.1086/345361

[22] Mora, J., Dary, O., Chinchilla, D. and Arroyave, G. (2009) Vitamin a sugar fortification in central America: Experience and lessons learned. MOST/US Agency for International Development, Washington DC.

[23] Gottlieb, J. (2012) Center for global development. Case study \#16: Prevention of neural-tube defects in Chile. http://www.cgdev.org/doc/millions/MS_case_16.pdf

[24] GAIN (2012) National food fortification program. http://wwws.gainhealth.org/programs/gain-national-foodfortification-program

[25] GAIN (2010) China soy sauce fortification project. http://www.gainhealth.org/project/china-soy-sauce-fortifi cation-project

[26] De Wals, P., Tairou, F., Van Allen, M., Uh, S.H., Lowry, R.B., Sibbald, B., Evans, J.A., Van den, Hof, M.C., Zimmer, P., Crowley, M., Fernandez, B., Lee, N.S. and Niyonsenga, T. (2007) Reduction in Neural-tube defects after folic acid fortification in Canada. New England Journal of Medicine, 357, 135-142.

\section{doi:10.1056/NEJMoa067103}

[27] Fiedler, J.L. and Macdonald, B. (2009) A strategic approach to the unfinished fortification agenda: Feasibility, costs, and cost-effectiveness analysis of fortification programs in 48 countries. Food and Nutrition Bulletin, 30, 283.

[28] Serdula, M., Pena-Rosas, J.P., Maberly, G.F. and Parvanta, I. (2010) Maximizing the impact of flour fortification to improve vitamin and mineral nutrition in populations. Food and Nutrition Bulletin, 31, S86-S93.

[29] Lotfi, M., Manar, M.G.V., Merx, R.J.H.M. and Naber-van den, Heuvel, P. (1999) Micronutrient fortification of foods: Developing a program. Journal of Food Technology in Africa, 4, 2-4.

[30] Spahn, K. (2009) How to effectively scale up interventions and actions that address malnutrition: Three cases from Helen Keller international. In: von Braun, J., Vargas Hill, R., and Pandya-Lorch, R. Eds., The Poorest and Hungry: Assessments, Analyses, and Actions 2020. IFPRI, Washington DC, 315-320.

[31] Haas, J.H. and Miller, D.D. (2006) Overview of experimental biology 2005 symposium: Food fortification in developing countries. The Journal of Nutrition, 136, 10531054.

[32] Mehansho, H. (2006) Iron fortification technology development: New approaches. The Journal of Nutrition, 136, 1059-1063.

[33] Allen, L. (2006) New approaches for designing and evaluating food fortification programs. The Journal of Nutrition, 136, 1055-1058.

[34] Mannar, V. and Gallego, E.B. (2002) Iron fortification: Country level experiences and lessons learned. The Journal of Nutrition, 132, 856S-858S. 